\title{
Apresentação: a ditadura continua para os índios
}

\author{
EDILENE COFFACI DE LIMA
}

RAFAEL PACHECO

O dossiê decorre do seminário Povos Indígenas: Memória, Verdade, Justiça, ocorrido no Centro de Pesquisa e Formação do Sesc-SP, como parte da chamada “ação em rede” Abril Indígena 2019. ${ }^{1}$ Por dois dias, especialistas indígenas e não-indígenas detiveram-se nos dilemas da proposição de (uma) justiça de transição para os povos indígenas, dada numa conjuntura política que só mostra a sua impossibilidade: a ascensão de um governo declaradamente anti-indígena e apologista da ditadura, capaz de homenagear torturadores e de defender sem pudores o uso da violência como política pública.

Compreendido no contexto de construção da memória pública do genocídio indígena no Brasil republicano, este volume se soma como contribuição interdisciplinar (e massivamente antropológica) às diversas iniciativas em proliferação desde a experiência das comissões da verdade, remarcando a recomendação da Comissão Nacional da Verdade (CNV) de continuidade e aprofundamento das pesquisas. ${ }^{2}$ A reunião de reflexões oriundas de pesquisa e atuação técnica, enquanto um dos prolongamentos do encontro, é acompanhada da disposição a alianças para o enfrentamento à ditadura passada e às ofensivas atuais. ${ }^{3}$

Não são inéditas denúncias de que se promove "genocídio" no Brasil. ${ }^{4}$ Povos indígenas, populações negras e de favela, especialmente, mobilizam este conceito para caracterizar como relativamente

1 Povos Indigenas: Memória, Verdade, Justiça. Curso de Formação (Perspectivas). CPF Sesc-SP. https://centrodepesquisaeformacao. sescsp.org.br/atividade/povos-indigenas-memoria-verdade-e-justica.

2 A CNV foi criada pelo decreto presidencial no 12.528 em 2012, vinculada à Casa Civil da Presidência da República e de existência restrita ao período de seu funcionamento (até 2014), com a missão apurar graves violações de direitos humanos ocorridas no período 1946-1988 (marco fixado pelo artigo $8^{\circ}$ do Ato das Disposições Constitucionais Transitórias da Constituição Federal de 1988).

3 Nesse mesmo propósito de dar continuidade às pesquisas, Edilene Coffaci de Lima e Jorge Eremites de Oliveira organizaram em 2017 o dossiê Remoçôes forçadas de grupos indígenas no Brasil Republicano, publicado na revista Mediações, da Universidade Estadual de Londrina. Vejam-se também Beltrão (2019) sobre a questão específica da saúde indígena na ditadura e Beltrão et alii (2018), abrangendo experiências na América Latina.

4 No último período, organizações indígenas, indigenistas e de direitos humanos vêm formalizando denúncias contra os governos brasileiros em órgãos internacionais (Sistema Interamericano de Direitos Humanos, Organização das Nações Unidas, em Genebra, e Tribunal Penal Internacional, em Haia) por violações de direitos humanos na implementação de projetos de grandes empreendimentos de desenvolvimento. Consultem-se "Apib denuncia à ONU a violação de direitos e o genocídio dos indígenas brasileiros" (Apib 2014), "Governo brasileiro é denunciado na ONU por violações de direitos indígenas" (ISA 2014) e "O que há contra Bolsonaro no Tribunal Penal Internacional” (Fabio 2019). 
a eles age o Estado, personificado, por sua vez, em seus governos e governantes. Povos indígenas até recentemente considerados "extintos", como os Xetá de Serra dos Dourados (Lima; Leite, infra), os Awã do Araguaia (Rodrigues, infra) e os Guató do Pantanal (Oliveira, 1995; 1996), engajados em suas lutas por reconhecimento e justiça, vêm fornecendo agora formas e estratégias de reconstrução da vida e do mundo, continuando a luta de reconhecidos líderes passados, e delegando às atuais e futuras gerações o seu lugar na história.

No tocante à ditadura, análises indígenas da questão, bem como da relação do Estado com essas populações, como as de Claudemir da Silva Xetá, Douglas Krenak, Sônia Guajajara e Sueli Maxakali, por exemplo, nos alertam que a ditadura ou a guerra ainda não acabou, reiterando a pertinência da questão e a premência de ações efetivas, de caráter transicional (Agência Senado 2017, Berbert 2017, Fiorott 2017, Marinho 2018).

Inquietações com o fenômeno do esquecimento são recorrentes. A paradoxal invisibilidade de histórias ante à vastidão e diversidade de registros, lembranças pessoais e coletivas, narrativas orais e histórias, documentos ou livros escritos em papel, materiais audiovisuais, com a oportunidade de serem convertidos em probatórios - os casos dos Xetá e dos Avá-Guarani nas regiões oeste e noroeste do Paraná são, neste sentido, exemplares (Lima; Leite, infra; Navarra, infra). O problema do esquecimento, assim, e a consequente vulnerabilidade das populações sobreviventes, emerge no debate sobre formas de ocultação executadas para viabilizar a reocupação de terras indígenas por não indígenas, questão norteadora das controvérsias jurídicas e políticas atuais.

\section{Armas}

Noções de justiça e verdade, conforme Mauro Almeida (2015), são armas dos cientistas sociais, manejadas em situações de atuação colaborativa entre comunidades tradicionais e profissionais que envolvem a enunciação da verdade - bem como, acrescentamos, a sua defesa - e a emissão de juízos sobre justiça e injustiça na vida social, como são definidos os processos envolvendo os direitos dessas populações, regularização fundiária especialmente. Para nós, aqui, tais noções têm centralidade, na medida em que constituem objetos e objetivos do campo que os envolve, a justiça de transição, compreendendo políticas de memória, verdade e justiça. ${ }^{5}$

Identifica-se atualmente uma "nova" época da violência política, marcada por uma "renúncia" por parte da política do sentido político da violência, assumindo-se "falta de motivação", tornando-a incidente do acaso e impossível de interpretação. Ao que uma tarefa da hermenêutica - e que a torna “inimigo" dos poderes - seja a caracterização dessas motivações (Malabou 2007, Žižek 2012). Neste nosso "tempo das catástrofes" - como a filósofa da ciência Isabelle Stengers (2015) define a corrente experiência de crise ambiental planetária e de iminente "extinção" da humanidade (cf. Danowski e Viveiros de Castro 2014, Krenak 2019, Žižek op. cit.) -, não cumpre, contudo, simplesmente estabelecer

5 "Justiça de transição", na acepção holística a que nos filiamos, compreende um conjunto de ações de vários tipos para enfrentar legados da violência de regimes autoritários ou conflitos/guerras civis, a fim do estabelecimento de novos marcos relacionais "democráticos" orientados pelo princípio de não repetição, o “Nunca mais” (Bickford 2004, UN Security Council 2004, ICTJ 2009). 
responsáveis, mas, e sobretudo, recolocar as questões já postas aos problemas, evitando-se (nos) a captura por "grandes narrativas" a partir de práticas e lutas locais minoritárias e marginalizadas, de povos e comunidades, que fornecem alternativas vívidas apesar de destruídas de sobrevivência, de modo a confrontar a racionalidade de Estado.

De fato, Theodor Adorno (1995) defendera caber à educação e à crítica após Auschwitz a criação de uma consciência (política) que evite a atualização de mecanismos infracivilizatórios que possibilitam a barbárie, instituindo à sociologia o imperativo de "não repetição" - o "Nunca mais" - no escopo de sua pretensa tarefa de autoconsciência crítica da sociedade, e ainda sob o efeito das atrocidades da Segunda Guerra Mundial. ${ }^{6}$ Noções de verdade e princípios de justiça arrancados às filosofias e lutas "populares", como defende Mauro Almeida (op. cit.), conformam uma “razão revolucionária”, não canônica, despretensiosa de universalismo e, por natureza, contra-estatal.

\section{História indígena no Brasil republicano: "esquema espoliativo", tecnologia de contato e remoções}

O século XIX marca ao menos duas alterações significativas na compreensão dos brasileiros da chamada "questão indígena": uma sendo sua transmutação de uma questão de mão-de-obra, como o era no período colonial, para uma "questão de terras", em que a política indigenista é subordinada às políticas fundiárias; a outra, o "estreitamento" dos espaços em que questões relativas aos indígenas são debatidas, restringindo-se a atribuição ao Estado, mesmo quando executada por instituições religiosas missionárias (Carneiro da Cunha 1992, Moreira Neto 1967). Os problemas pioraram no momento atual, remarca o intelectual indígena Ailton Krenak, quando a violência não é mais como era antes, dirigida ao território - "como uma disputa por recursos" -, mas compreende um discurso racista "a ponto de justificar violência dirigida contra a pessoa, de uma maneira descarada" (Farias 2020).

Recentemente, movimentos no campo da história indígena na antropologia brasileira têm se centrado no período republicano. O impulso que a temática tomou no país há mais ou menos três décadas é notável. Contudo, os esforços - motivados em parte pelo subsídio a reivindicações territoriais indígenas no período constituinte (1987-8) - centraram-se no período imperial (cf. Carneiro da Cunha 1992), mantidas certas lacunas quanto a outros períodos.

Da ditadura civil-militar iniciada em 1964 dispúnhamos de sínteses acerca da região amazônica, propriamente os impactos do Plano de Integração Nacional (PIN) implementado após o AI-5, do qual a obra de Shelton Davis Vitimas do Milagre (1978) e registros em denúncias apresentadas ao Tribunal Russell $(1974-76,1980)$ são documentos notórios. Ainda, é preciso remarcar, os estudos foca(va)m desde a perspectiva da "política indigenista dos governos militares" ou da "relação do Estado com os povos indígenas", o exame das implicações da doutrina de segurança nacional - o "binômio" segurança e desenvolvimento - no indigenismo (Alexandre 2017, Dias Filho 2015, Fernandes 2013, Heck 1996, Prado 2018). Um apanhado detido às especificidades do Brasil meridional, compreendendo os povos

6 A ideia de não repetição, sintetizada na fórmula "Nunca mais" é encampada por povos indígenas, como no mote da campanha internacional “Sangue indígena, nenhuma gota a mais”, capitaneada pela Articulação dos Povos Indígenas no Brasil (Apib). 
Xetá (PR), Charrua (RS), Guarani, Mbya, Ñandeva, Kaiowá (ES, MS, PR, RJ, RS, SC, SP), Kaingang (PR, RS, SC, SP), Ofaié (MS) e Xokleng (PR, SC), ainda está por ser feito.

Com o advento das comissões da verdade novos temas e questões de trabalho foram possibilitadas, e antropólogos, historiadores, jornalistas e juristas passaram, então, a realizar estudos centrados nas memórias de eventos compreendidos no período 1946-1988 a partir das perspectivas indígenas, enquadrando-as nos temas, problemas e objetivos políticos inscritos no processo transicional brasileiro.

Iniciativas indígenas conformadas nessa circunstância operam inflexões conceituais e metodológicas no tratamento da ditadura que desde já, embora timidamente enunciadas, não permitem retrocessos à instanciação de um arcabouço conceitual, legal e político-institucional que reconheça a especificidade das histórias indígenas. Consequentemente, no processo de caracterização de "graves violações de direitos humanos" dos povos indígenas, diversas noções conexas, ilusoriamente tidas estáveis pela teoria social, são reabertas: violência, genocídio e etnocídio, ditadura, resistência, reparação... (Calheiros 2015, Lima e Pacheco 2017, Rosely Pacheco 2018, Pierri 2014, Pierri e Zelic 2014, Ramos 2018, Viveiros de Castro 2016).

Como argumentamos alhures (Lima e Pacheco 2017), o conjunto documental organizado pelas pesquisas dessas comissões (documentos oficiais, fotografias, filmes e depoimentos, entre outros) nos oportuniza revisitar a história indígena no período republicano do ângulo de documentos que nos dão testemunhos da violência, e delineiam uma "radiografia" do sistema repressivo do regime integracionista (vigente até a CF 1988), buscando uma sistematização de seu aparato legal, métodos e técnicas. Constituem, com efeito, acervos para a história indígena e documentos para as lutas indígenas. E o desafio colocado a partir de então consiste em qualificar formulações indígenas de acontecimentos históricos reputados ao Estado, dimensionando seus impactos e efeitos, bem como possíveis formas reparatórias.

As remoções forçadas de grupos indígenas constituíram até certo ponto instrumento de liberação de terras para reocupação por frentes de expansão, sendo emblemáticos para a CNV (2014, v. II: 209-10) os processos de exploração minerária e hidrelétrica na Amazônia e na Bacia Platina no escopo do Plano de Integração Nacional (PIN) nas décadas no pós AI-5. A CNV reportou a emissão de "certidões negativas" da presença de índios como um dos expedientes exemplares de extinção oficial fraudulenta de povos indígenas em áreas realmente habitadas solicitadas por empresas agroindustriais. Foi assim, por exemplo, que o chefe da Funai, General Ismarth Bandeira de Melo concluiu pela remoção dos Nambikwara em Mato Grosso em favor da solicitante Vila Bela Agropastoril S/A: "Logo que atraídos e pacificados e transferidos para a reserva definitiva, esta presidência poderá atender ao pedido de V.Sa” (CNV 2014, v. II: 209).

Considerando as experiências de "contato" dos Xetá (Silva 1998), dos Kajkwakratxi/Tapayuna (Lima, D. 2012) e dos Ofaié (Borgonha 2006, Dutra 2004) com o SPI e a Funai, caracteriza-se uma "tecnologia do contato e das remoções" em que "sobressaem não as famosas miçangas, machados e espelhos de outrora, mas sim suas ações determinadas de extermínio e redução, com o envenenamento dos recém-contatados [...] e o deslocamento forçado de seus territórios", tratando-se de "estratégias" governamentais que resultaram no "estabelecimento de grupos indígenas fora de seu território origi- 
nal", variando-se neles apenas o meio de transporte, "caminhões para os Xetá e Ofaié e avião para os Tapayuna" (Lima, E. 2016:28-9). ${ }^{7}$

Tais questões têm sua importância renovada em função do advento na jurisprudência brasileira da chamada tese do "marco temporal", pelo que apenas seria reconhecido direito à posse de terras a povos indígenas nelas efetivamente localizados na data de promulgação da Constituição de 1988. Em termos de atuação antropológica técnica ou aplicada, a fundamentação (documental) das reivindicações territoriais indígenas tem de ser feita em dois movimentos, não apenas pela constatação da antiguidade da ocupação (elemento fático), como também por uma justificação dos motivos de nelas não estarem em 1988 e atualmente, em que se impõe o tema das remoções forçadas como um motivo da história dos povos indígenas. ${ }^{8}$

Justamente, na década de 1930 o então Serviço de Proteção aos Índios (SPI) é subordinado administrativamente ao Ministério da Agricultura, ali permanecendo até a reforma ministerial implementada pelo general Arthur da Costa e Silva em 1967. Hélio Jorge Bucker, chefe da 5 a Inspetoria Regional do SPI, em depoimento à Comissão de Inquérito do Ministério do Interior - a chamada "Comissão Figueiredo" -, relatou a existência de um "esquema espoliativo" liderado pelo Ministério da Agricultura através de seu órgão de terras (DTC) e envolvendo servidores do SPI, governos, personalidades políticas e atores econômicos locais (Relatório Figueiredo, 1967, p. 3.952-3.953; CNV, 2014, v. II, p. 208) - o que, posteriormente, será reafirmado na chamada “CPI do Índio”, instalada no Congresso Nacional em fins dos anos 1970, quando se expõe a vinculação da Funai, no âmbito do Ministério do Interior, às políticas de desenvolvimento econômico-financeiro aplicadas localmente, dando continuidade, de certo modo, às práticas do já extinto SPI (CPI Funai 1977: 44-5, CNV 2014, v. II: 208).

O quadro "devastador" em que se encontrava o SPI, submetido aos interesses da produção agrícola nacional, é detalhado pelo jornalista Rubens Valente (infra), em artigo original, manuscrito não publicado em seu Os fuzis e as flechas - histórias de sangue e resistência indígena na ditadura (2017). A escassez de recursos financeiros a que o SPI era historicamente submetido redundava em vulnerabilidade extrema das comunidades e aldeias: "Sem recursos, o SPI passou a arrendar terras para fazendeiros vizinhos, a vender madeira, a autorizar o funcionamento de serrarias e a permitir criação de gado alheio em terras indígenas", medidas que, longe de serem desconhecidas do órgão tutelar, eram ao contrário incentivadas, compondo uma de suas fontes principais de recursos, a chamada Renda Indígena. Os in-

\footnotetext{
7 Atribuem-se à Companhia Brasileira de Imigração e Colonização (Cobrimco), empresa colonizadora paulista, do grupo Bradesco, que recebeu a concessão das terras indígenas pelo governo do Paraná em 1951-2 e procedeu ao seu loteamento. Em ofício ao Conselho Nacional de Proteção aos Índios (CNPI), o antropólogo e professor da UFPR José Loureiro Fernandes relatou terem caminhões reputados à Cobrimco sido vistos mais de uma vez "conduzindo os índios para fora da Serra dos Dourados para destinos que ninguém ao que parece até agora tentou averiguar", remarcando que na região "[p]essoas temem fazer denúncias” (CEV-PR 2017, L. Fernandes 1958, Silva 1998).

8 A "tese do marco temporal" de ocupação emerge em meados dos anos 2000 para dar solução final aos impasses na demarcação da TI Raposa Serra do Sol (RR) no Supremo Tribunal Federal (Pet. 3388), no qual a corte acompanhou formulação do ministro Teori Zavascki que estabelecia a data de promulgação da Constituição (05 out. 1988) como parâmetro - condicionante - para reconhecer a posse indígena. Exceção prevista pelo jurista é a ocorrência de "renitente esbulho", i.e., conflito possessório materializado por "circunstâncias de fato" (i.e., conflito violento) ou "controvérsia possessória judicializada” continuados até a data do marco temporal, e que de todo modo, não se confunde com "desocupação forçada, ocorrida no passado" (STF, ARE. 803/462 - AgrR/MS). A tese do marco temporal é extensamente debatida na coletânea recentemente publicada por Carneiro da Cunha e Barbosa (2018), que traz, entre outras contribuições, o parecer do jurista José Afonso Silva, e na dissertação de mestrado de Raquel Osowski (2017).
} 
dígenas permaneciam “alheios aos números”, enquanto o seu patrimônio era pulverizado por servidores do órgão em gastos administrativos por definição de responsabilidade da União.

A disputa pela sucessão presidencial entre militares, conforme Valente identifica, figura como um dos elementos definitivos no processo que culminaria na extinção do SPI: o combate à corrupção, um dos argumentos mobilizados pelos militares para justificar o golpe de 1964, é retomado pelo general Albuquerque Lima, Ministro do Interior, e agora, uma vez que corrupção era comparada a "atos de guerra revolucionária" pelo Ato Institucional no 1 (AI-1, 1964), eram dadas as "razões políticas" para determinar-se um inquérito interno - cujo resultado é o conhecido Relatório Figueiredo - e consequentemente a extinção do órgão. ${ }^{9}$ Assim, tem-se uma faceta complementar à história e à sociologia das agências indigenistas, realçando o seu aspecto de espoliadora oficial dos povos indígenas e a longa história de militarização da política indigenista. ${ }^{10}$

Contribuições antropológicas críticas à complexidade do alcance simultaneamente das violações e das medidas reparatórias, tematizado seu caráter coletivo, são oferecidas pelas trajetórias da longa e aguerrida resistência Âwa do Araguaia à "extinção", pelo que Patrícia de Mendonça Rodrigues (infra) explora a compreensão do alcance da proporção de "reparações históricas” da sociedade brasileira.

Os valentes Avá-Canoeiro dos Araguaia, reconhecidos como o povo mais resistente do Brasil Central - "que preferiam a morte a entregarem-se ao inimigo" -, sofreram na década de 1970 uma brutal captura pela Frente de Atração da Funai, que os removeu de seu território, no qual se instalaria uma unidade rural da Fundação Bradesco, e os confinou na Fazenda Canoanã, motivando-se, assim, o contato com os indígenas - na perspectiva de sua remoção. No cativeiro, por cerca de três anos os Âwa sofreram diversos abusos, físicos, sexuais e emocionais traumáticos; amarrados numa espécie de "jaula a céu aberto", eram expostos como animais “domados” à população local de forma espetacularizada. Transferidos novamente em 1976 para a aldeia Canoanã, dos Javaé, seus inimigos históricos, foram, finalmente, subjugados, incorporados ali como wetxu ("cativos de guerra") e subalternizados. Os fatos violentos eram sempre amenizados e mesmo ocultados nos relatos dos documentos da Funai e na imprensa, chegando ao limite de serem os $\tilde{A} w a$ considerados "extintos" ou "em vias de extinção". Rodrigues enfatiza que a derrota imposta pelo Estado à resistência $\tilde{A} w a$ resultou na perda de sua autonomia e terras, compreendido todo o processo no âmbito do "racismo colonial” (cf. Quijano 2005).

Note-se que o grupo Bradesco se envolve no esbulho de terras indígenas de forma consecutiva: no período 1940-60, com os Xetá, no Paraná; e, na sequência, na década de 1970, com os Âwa, no atual estado do Tocantins. Notável, inclusive, é a similaridade das histórias desses dois povos tupi-guarani. A um só golpe também, a construção da UHE Itaipu Binacional atinge tanto os Avá-Guarani quanto os Xetá (Lima; Leite, infra; Navarra, infra). De certa forma, os nós da rede de violência e esbulho

9 O chamado Relatório Figueiredo vem sendo objeto de múltiplas leituras. Guimarães (2015) enfrenta-o desde seu teor documental propriamente; Azola (2017) explorou seu conteúdo relativo à região e aos povos indígenas no sul do Brasil, enfatizando a ideologia do "ruralismo"; Beltrão e Cardeal (2018) analisam as práticas de exploração madeireira e arrendamentos de terras indígenas entre 1964 e 1985.

10 As relações entre militares e povos indígenas, denominada por "militarização da(s) política(s) indigenista(s)" são tratadas por Gagliardi (1986), Heck (1996) e Prado (2018). 
territorial que alcançava os povos indígenas em diferentes quadrantes aparecem atados pelos mesmos personagens, públicos e privados, eventualmente atuando em estreita colaboração.

\section{Verdades reveladas: profundo desconhecimento}

O que Paula Berbert (infra) afirma sobre a CNV é pertinente: forneceu "parâmetros" para estimarmos a dimensão do "apagamento histórico" produzido no Brasil sobre, de um lado, a história indígena, e a história da ditadura de 64 , de outro. Se, como ela argumenta, a estimativa de pelo menos 8.530 indígenas mortos em decorrência de políticas estatais entre 1946-1988 abalou a frágil certeza de cerca de 434 oficialmente reconhecidos "mortos e desaparecidos políticos", ao aspecto contábil precede o estabelecimento da tese do caráter "sistêmico" das violações dos direitos indígenas, isto é, a compreensão, primeiro, do englobamento das políticas indigenistas no projeto global do Estado, e, depois, o estabelecimento das correlações entre as violações perpetradas e os objetivos das políticas estruturais de Estado, relativamente aos direitos e interesses indígenas. ${ }^{11}$

No Brasil os debates públicos e uma agenda (mínima) de ação hoje se centram nas Recomendações do Relatório da CNV (2014) e nas Resoluções da I Conferência Nacional de Política Indigenista, no Eixo 6 - Direito à memória e à verdade (I CNPI 2015), encerrando um rol de medidas sob responsabilidade do "Estado (Brasileiro)" que garantam e promovam a continuidade física e cultural dos povos indígenas. Algumas das proposições da I CNPI, em seu diálogo com os códigos das políticas de memória, verdade e justiça, além de adensarem um possível teor "reparatório" a direitos indígenas já constitucionalmente estabelecidos e demais políticas públicas, extrapolam a datação oficial da ditadura civil-militar de 64, compreendendo o problema nos marcos do colonialismo, quer dizer, as balizas realmente relevantes são aquelas dadas pela história indígena. Nesses outros termos, a ditadura potencializa teorização mais ampla, com consequências (políticas) ainda não mensuráveis.

Em julgamentos inéditos da Comissão de Anistia (órgão que, a seu modo, oficializa o reconhecimento de que o Estado perseguiu politicamente a/o requerente), inaugurais da participação de coletivos indígenas nos mecanismos transicionais, estes dois elementos são decisivos para efeitos ulteriores, um sendo o reconhecimento oficial do fato do genocídio, e o outro a superação da perspectiva individualizada - essencial à teoria dos direitos humanos - como única possível para definir danos, penas e medidas reparatórias.

O primeiro caso, de Tiuré Potiguara, perseguido por apoiar a resistência de povos indígenas frente às ações dos governos militares (pelo que teve de exilar-se no Canadá, considerando-se ser o seu reconhecimento como "refugiado político" por aquele país a primeira condenação internacional do estado brasileiro por crime politico contra indigena), obrigou a advogada Sueli Bellato, relatora do caso na Comissão de Anistia, a reconhecer:

11 A oficialização de “mortos e desaparecidos políticos” se dá por reconhecimento da Comissão Especial sobre Mortos e Desaparecidos Políticos (CEMDP). Sobre povos indígenas, a CNV trabalhou com 10 casos emblemáticos documentados, remarcando que o número de vítimas a ser computado, considerando a existência no Brasil de 305 povos indígenas, deverá ser "exponencialmente maior" ao apresentado. Na formulação da CNV, “[n]ão são esporádicas nem acidentais essas violações: elas são sistêmicas, na medida em que resultam diretamente de políticas estruturais de Estado, que respondem por elas, tanto por suas ações diretas quanto pelas suas omissões” (CNV 2014, v. II, p. 204). 
"Eu precisei abstrair e me afastar dos conceitos de perseguido político tradicional, porque ele não era o estudante expulso da universidade porque participou de um protesto e nem o operário demitido da fábrica porque fez greve: era alguém que lutava quase que pelo direito de sobreviver" (Passos 2013: s./p.). ${ }^{12}$

O segundo caso, dos Aikewara (Suruí), vitimados pelos marehai ("soldados") do Exército Brasileiro durante as operações de extermínio da Guerrilha do Araguaia. Ao anunciar o resultado do julgamento (que acolheu 13 de 16 requerimentos), o então presidente da Comissão de Anistia, Paulo Abrão, firmou entendimento de que "o conjunto de uma comunidade indígena" havia sido vítima da ditadura.

Os efeitos continuados das intervenções pelos marehai no território aikewara são abordados pelas falas de dois aikewara, moradores e professores da TI Sororó. Murué Suruí (infra) aborda o problema do corte feito na terra indígena pela BR-153, implementada pelo Exército, que exclui parcela considerável do território tradicionalmente ocupado, priva os Aikewara do acesso à argila com que produziam cerâmicas e possibilita a ocorrência de queimadas, acidentais ou deliberadas (criminosas), pela intensificação do tráfego de carros. Tiapé Suruí (infra) pontua a impossibilidade de reparação da cicatriz deixada no meio do povo, traumas de violência direta, percepção de perda da língua, do costume, do modo social e da organização, caracterizando o impacto de ordem, diga-se, cultural, e a consequentemente necessidade de reparação coletiva, "até mesmo porque", consigna ele, "a comunidade toda sofreu". Como Iara Ferraz (infra) aponta, a compreensão da dimensão coletiva da violência, porém, não encontrou correspondência na medida reparatória aplicada, individualizada e pecuniária, restando insuficiente para "reparar" na medida reivindicada pelos Aikewara: a devolução, mediante demarcação, das suas terras tomadas pelo Estado (cf. Calheiros 2015).

Em outra oportunidade, Carlos Marés de Souza Filho, reconhecido jurista, professor e socioambientalista, reconhece que o amplo movimento de apoio e alianças com os povos indígenas conformado no período da "redemocratização", a partir das décadas de 1970 e 1980, deu-se pelo convencimento dos setores urbanos - estudantes, trabalhadores, militantes etc. - de que a violência perpetrada pelos militares da ditadura contra eles era análoga àquela que povos indígenas, negros, camponeses, vinham sofrendo sem recesso ao longo dos séculos. ${ }^{13}$ Constatação irrefutável, mas que, imersa no caldo da ainda restrita compreensão da sociedade brasileira acerca da "abrangência da ação de um Estado repressor na vida dos cidadãos" (CNV 2014, v. II: 206), permeada que é de incertezas perigosas, pode resolver inapropriadamente a questão da ditadura no colonialismo - "o extermínio indígena existe desde 1500" -, desfazendo-se, assim, a especificidade histórica dos recentes “anos de chumbo".

O impasse está, até o momento, no debate acerca da natureza específica (étnica) e da abrangência (coletiva) da violência anti-indígena, elementos que dão contornos à categoria genocídio: o propósito de "integrar" (= assimilar) é eufemismo para a imposição de um modo de vida sobre outro, tendo-se

12 Aprovado por unanimidade o parecer de Bellato, Tiuré foi reconhecido "anistiado político", recebendo a título de reparação indenização em dinheiro, que alegou pretender aplicar numa proposta de criação de uma espécie de comissão nacional da verdade indígena: "Eu quero começar a pesquisa pelos locais onde passei e vi muita coisa, mas pretendo também estimular outras aldeias e outros povos a aderirem a esta luta" (Passos 2013).

13 Seminário "Dizer o indizível nos museus: Violência contra indígenas", MAE-UFPR/IBRAM, Curitiba/PR, mai. 2017. 
por alvo, a despeito de eventual incidência sobre indivíduos, povos inteiros e enquanto tais (cf. Calheiros 2015, Lima e Pacheco op. cit.).

A discussão é fundamental, remetendo à qualificação limitada de "graves violações de direitos humanos" operada pela CNV, com consequente redução das suas investigações, prioritariamente, a casos de prisão arbitrária, tortura, execução sumária e desaparecimento forçado (CNV, 2014, v. I, Cap. 7, p. 277-99). Face às especificidades da "questão indígena", as limitações desse modelo embasado em normativa e jurisprudência internacionais se explicitam na ausência do crime de genocídio no rol de graves violações de direitos humanos fixadas no Relatório da CNV, reiterando-se, de certo modo, a incerteza incômoda quanto a serem as violências contra indígenas então documentadas politicamente motivadas.

O que resta da ditadura nesse caso, portanto, é um problema de ordem conceitual, concernente ao elemento da intencionalidade no conceito (moderno) de violência, e, por extensão, do crime de genocídio. Impõe-se aí delimitar a ideologia dominante no pensamento e norteadora da legislação indigenista ao longo de todo o século XX: o paradigma integracionista, equivocadamente definido como assimilação cultural, a fim da eliminação progressiva dos povos indígenas mediante a transformação metódica (e forçada) de seus modos de vida.

Por definição, no problema da violência “[a] ênfase na intenção é importante”, consigna Arblaster (2019: 803-4), "uma vez que a cirurgia e a odontologia podem causar dor e há a probabilidade de envolverem a perda de partes do corpo - mas o único propósito dessas inflições é o bem-estar do paciente"; a tortura, ao contrário, é violência: causar dano, dor e sofrimento deliberadamente na vítima em benefício de outrem. O núcleo da intencionalidade, apesar de não determinante em termos de definição, afasta a acepção vigente e vulgar da violência como agressão física, e que não compreende formas da violência que não têm por imagem conceptual conflitos diretos, "de fato" ou "corpo a corpo".

Numa definição contundente, trata-se do que a filósofa e educadora Cristine Takuá (infra) em sua fala designa como "estupro da essência da epistemologia do ser de cada povo", a desestruturação de línguas, crenças, territórios, compreendendo também as persistentes ausências das histórias indígenas em livros de história e a negação ao reconhecimento pelas universidades de seus conhecimentos e modos de pensar. O ponto central, destaca Cristine, é a contínua "negação da existência" dos povos indígenas - na colonização, na ditadura, em 2019; injustiça que não recai apenas sobre os humanos, como também é expressa na recusa à escuta dos outros seres viventes: "Quem está escutando a paca, cotia, lontras, abelhas, as formigas, as sumaúmas e todos os seres sagrados visíveis e invisíveis que estão vivendo dentro da floresta? Ninguém! Então a nossa luta pelos territórios é para que os cemitérios sejam respeitados, e para que esses seres que permitem que a gente possa viver nosso equilíbrio, também continuem vivendo". 


\section{Povos indígenas e ditadura}

Pode-se afirmar com convicção serem povos indígenas vítimas de atos de exceção durante a ditadura militar? E, ampliando o escopo da questão, pode-se levar às últimas consequências a afirmação de que a ditadura continua?

A partir da afirmação de Sueli Maxakali de que "a ditadura não acabou”, Paula Berbert (infra) encara três perguntas: o que caracteriza(ria) este regime de exceção? Como ele se instalou entre os tikmüun_maxakali? E, finalmente, como pode continuar operando até agora, apesar da reconstitucionalização do país?

A ditadura é expressa no modo mesmo de relação que o Estado e seu povo mantêm com os Tikmüun, designada "assimilação", definida pelo esbulho de terras tradicionalmente ocupadas (e originárias), constantes e impunes assassinatos de parentes e, de modo geral, arbítrio direto sobre suas formas de viver. Em tais formulações, emergidas na circunstância de reelaboração das experiências com a Guarda Rural Indígena (Grin) e do Reformatório Krenak, é reconhecido ser a chegada de tais "forças de morte" aos Tikmüun_maxakali coeva à dos ãyubuk (brancos), remontando à "guerra justa" desencadeada pelo imperador Dom João VI contra os chamados índios "botocudos” em Carta Régia de 1808.

No fim das contas, de uma perspectiva indígena, o que embasa a percepção da persistência da ditadura é o paradigma assimilacionista de relacionamento, que, numa longa duração, repete agora, nas palavras do mandatário da República Jair Bolsonaro, que em seu governo não será demarcado "um centímetro" sequer de terras indígenas (Resende 2018). Não custa lembrar que as finalidades da guerra justa deflagrada no Império eram: assenhoramento de suas habitações, convencimento da superioridade real das armas do Estado, sujeição ao jugo das leis e sua transformação em vassalos úteis. A assimilação, assim, configurada como uma política de Estado, é uma ação incidente simultaneamente sobre terras e corpos. É desse modo que no atual tempo dos direitos a demarcação das terras indígenas serve de indicador para medir a democracia, e pode ser considerada também medida transicional e reparatória: na medida em que os Tikmüun_maxakali puderem retornar às terras onde há os cantos dos yãmĩyxop, povos-espíritos da floresta, é que se poderá pensar efetivamente em democracia.

O fato mais evidente é que talvez estejamos, nós e os indígenas, usando o mesmo conceito - no caso, ditadura - para falarmos de coisas diferentes, servindo-nos dele de distintas formas, o que tem alto potencial para acentuar um daqueles mal-entendidos linguísticos conhecido como "falsos amigos". Enquanto, de um lado, tendemos a nos prender à compreensão a partir das balizas cronológicas que delimitam períodos democráticos com a realização de eleições livres, índice que imaginamos ser um marcador incontestável da participação popular; os indígenas estão a nos oferecer uma outra compreensão - no caso, a partir da denúncia da incessante violência que lhes é dirigida, com ou sem a realização do escrutínio eleitoral.

A analogia entre a prática dos militares (pré e pós 64) e o governo Bolsonaro (sem partido), que já em sua primeira medida governamental intentou alocar o órgão indigenista, novamente, no Ministério da Agricultura (MAPA), é compreendida por Manuela Carneiro da Cunha (infra) para caracterizar 
a situação "inédita” em a questão indígena é tratada, notadamente atacada, em primeiro ato de governo. O oximoro se repetiria: o órgão responsável por defender os direitos indígenas, especialmente as terras indígenas, seria subordinado ao ministério com atribuição de executar a política de desenvolvimento agrícola, atendendo-se às solicitações do setor ruralista com a flexibilização dos dispositivos legais de proteção e consequente liberação desses territórios para implementação de projetos econômicos agroindustriais.

O ponto na reflexão de Carneiro da Cunha é o papel da pesquisa, naquele contexto, para o enfrentamento da ditadura, que se fez mediante a análise de conflitos de terra e identificação de lacunas de conhecimento, com protagonismo das organizações não governamentais, em vista do cerceamento da pesquisa nas universidades. A proliferação da pesquisa histórica nessa circunstância, possibilitadora de acúmulo de debates e documentação, foi fundamental para a subsequente formulação dos direitos indígenas na Constituinte, pelo que também se entrevê o papel da sociedade civil e uma faceta da ampla aliança articulada entre os povos indígenas e os mais distintos parceiros para assegurar o reconhecimento de seus direitos no novo texto constitucional.

Atualmente, de um lado, pesquisas colaborativas entre povos tradicionais e cientistas compreendendo a importância e as contribuições dos conhecimentos de povos indígenas e comunidades tradicionais locais para a biodiversidade, no escopo das agendas climática e socioambiental planetárias, e, de outro, a crítica à interpretação jurídica dos direitos territoriais indígenas sob a tese do "marco temporal" de ocupação, pelo que o STF pretende "tirar o direito de retorno de populações deportadas", constituem iniciativas que recolocam o papel da pesquisa, em sintonia com problemas correntes.

Numa composição entre o direito e a antropologia, Júlia Navarra (infra) explora o caso "amplamente reconhecido e fartamente documentado" da espoliação das terras Avá-Guarani na Bacia Platina, e especificamente na porção oeste do Paraná, em que o discurso do "vazio demográfico" foi instrumento de transformação oficial de terras efetivamente ocupadas em "devolutas", aptas à alienação por empresas colonizadoras e particulares. ${ }^{14}$

Há quase um século pelo menos, historiciza Navarra, os Avá-Guarani vêm sofrendo renitente esbulho, decorrente de empreendimentos governamentais mais amplos de "integração" territorial das áreas de fronteira e de aproveitamento dos recursos hídricos da Bacia Platina: entre 1930-1960 o Estado do Paraná acelera as titulações de áreas indígenas a ocupantes não-indígenas; na década de 1970, no bojo do Projeto Integrado de Colonização (PIC) na região de Ocoí, o governo cria o Parque Nacional do Iguaçu, consolidando a expulsão de diversas aldeias e pequenos proprietários (parte da comunidade avá retoma áreas esbulhadas, sendo posteriormente expulsa novamente); nos anos 1970 do "Milagre Econômico", por força da construção da UHE Itaipu Binacional - maior empreendimento do tipo à época -, ao menos 32 aldeamentos avá-guarani foram completamente submersos, "alguns deles nos quais as pessoas só descobriram que teriam que sair quando viram a água subindo repentinamente", seguindo-se sucessivas fraudes por servidores do Incra, órgão então responsável pelo reassentamento

14 Sobre o discurso, ou retórica, do "vazio demográfico" e sua instrumentalização pelo Estado para o acobertamento de práticas criminosas que produzem vazios "reais", vejam-se Mota (1994) e Tomazi (1997) sobre a colonização do Paraná e Ramos (1993) sobre o caso dos Yanomami em Roraima. 
dos deslocados, como a negação do reconhecimento dos indígenas ocupantes (designados deliberadamente "mestiços" ou "camponeses"), e mesmo a sua expulsão, mediante espancamentos, incêndio de casas, despejos, ameaças de tiros, remoções forçadas em caminhões etc.

Além do esbulho da terra, contra o qual os Avá-Guarani continuam oferecendo persistente enfrentamento, a instalação de empreendimentos público-privados de colonização e infraestrutura no território indígena causou o sarambi ("esparramo"), dispersão de parentes e grupos familiares avá-guarani para fora das áreas tradicionalmente ocupadas. ${ }^{15}$ Outra vez encontramos os Xetá, que designam como extravio o processo similar - resguardadas as peculiaridades respectivas - de dispersão forçada de seus parentes retirados da Serra dos Dourados, no noroeste paranaense.

O aludido impasse na caracterização da "motivação política” do terrorismo estatal anti-indígena, que pode obstar a participação de indígenas no processo transicional brasileiro, é revelador do conflito de ontologias e epistemologias. Conquanto cabe a nós (um "nós" inclusivo, porém indeterminado, aberto a adesões) a atualização do balanço da "história indígena" no período republicano informada por histórias indigenas na/da ditadura dadas nesses processos de documentação da violência. A dinâmica complexa entre a longa história do colonialismo e a delimitada pela história da ditadura é constante, e mesmo uma marca, das reflexões aqui coligidas.

Finalmente, com isso, esperamos confluir esforços ao incipiente debate acerca das especificidades da justiça de transição para os povos indígenas, extraídas da própria história indígena, única instância capaz de conferir sentido real a danos, dores e sofrimentos, e fundamentar adequadamente medidas reparatórias. Este reconhecimento será o primeiro movimento efetivo para começarmos a pensar numa justiça de transição para os povos indígenas em sentido forte.

À frente, a perspectiva é a de seguir, como diz Ailton Krenak, "enterrando" os profetas do fim dos povos indígenas.

Edilene Coffaci de Lima é Professora do Departamento de Antropologia e do Programa de Pós-graduação em Antropologia e Arqueologia da Universidade Federal do Paraná (UFPR); e Membro do Comitê Estadual de Memória, Verdade e Justiça do Estado do Paraná (DEDIHC/Seju). Colaborou com a Comissão Estadual da Verdade do Paraná "Teresa Urban" (CEV-PR) nas pesquisas sobre povos indígenas, e especificamente no caso Xetá.

Rafael Pacheco é antropólogo, mestre em Antropologia pelo PPGAA/UFPR e doutorando no Programa de Pós-graduação em Antropologia Social da Universidade de São Paulo (USP); e Membro do Fórum sobre Violações de Direitos dos Povos Indigenas (FVDPI/Andhep). Colaborou com as comissóes da verdade Nacional (CNV), Estadual de São Paulo "Rubens Paiva" (CEV-SP) e Estadual do Paraná "Teresa Urban" nas pesquisas sobrepovos indígenas, e especificamente no caso Xetá.

15 Note-se aqui que também os Guarani do Mato Grosso do Sul chamam de Nemosarambipa ("esparramo") a dispersão de aldeias e famílias extensas após a implementação de fazendas de gado em suas terras (Colman 2017). 


\section{REFERÊNCIAS BIBLIOGRÁFICAS}

AGÊNCIA SENADO. 2017. "A ditadura continua para os índios, afirmam participantes de audiência pública”, 20 abr. 2017. Disponível em: <https://www12.senado.leg.br/noticias/ materias/2017/04/20/a-ditadura-continua-para-os-indios-afirmam-participantes-de-audienciapublica>. Consulta em 18/02/2020.

ADORNO, Theodor W. 1995. "Educação após Auschwitz”. In: Adorno, T. W. Educação e Emancipação. Tradução de Wolfgang Leo Maar. São Paulo (SP): Paz e Terra. Disponível em < https://rizomas.net/arquivos/Adorno-Educacao-apos-Auschwitz.pdf>, acesso em 17 abr. 2020.

ALEXANDRE, André Demetrio. 2017. A (In)Justiça de Transição para os povos indígenas no Brasil. Dissertação de Mestrado em Direito Econômico e Socioambiental. Curitiba: Programa de Pósgraduação em Direito, Escola de Direito da Pontifícia Universidade Católica do Paraná.

ALMEIDA, Mauro W. B. "As ciências sociais e seu compromisso com a verdade e a justiça”. Mediaçôes 20(1):260-284. Disponível em: <http://www.uel.br/revistas/uel/index.php/mediacoes/ article/view/23265/pdf_12>. Consulta em 18 fev. 2020.

APIB. "Apib denuncia à ONU a violação de direitos e o genocídio dos indígenas brasileiros", Articulação dos Povos Indígenas no Brasil, 24 nov. 2014. Disponível em <http://blogapib.blogspot. com/2012/11/apib-denuncia-onu-violacao-de-direitos.html?m=1>, acesso em 17 abr. 2020.

ARBLASTER, Anthony. 2008. "Violência”. In: William Outhwaite \& Tom Bottomore (ed.). Dicionário do pensamento social do século XX. $2^{\mathrm{a}} \mathrm{ed}$. Rio de Janeiro (RJ): Zahar.

AZOLA, Fabiano A. 2017. O Relatório Figueiredo e os indios no sul do Brasil. Monografia em Ciências Sociais. Curitiba: Departamento de Antropologia,, UFPR. Disponível em <https://www. tellus.ucdb.br/tellus/article/view/564>, acesso em 17 abr. 2020.

BELTRÃO, Jane Felipe. 2019. “Povos indígenas, saúde e ditadura”, Tellus 19(39):61-69. Disponível em <https://www.tellus.ucdb.br/tellus/article/view/564>, acesso em 17 abr. 2020.

BELTRÃO, Jane F.; CARDEAL, Paulo Victor Neri. 2018. "Povos indígnas, esbulho territorial e anos de chumbo: leituras do Relatório Figueiredo, In: Beltrão et al. (Org.). 2018. "Dossiê Povos indígenas e Ditaduras na América Latina”, Espaço Ameríndio 12(2):290-312. Disponível em <https://seer.ufrgs.br/EspacoAmerindio/article/view/83499/53068>, acesso em 17 abr, 2020.

BELTRÃO, Jane F.; SILVA, Sergio B.; SAMPAIO, Patricia M.; FERNANDES, Rosani de F. (Org.). 2018. “Dossiê Povos indígenas e Ditaduras na América Latina”, Espaço Ameríndio 12(2):4-260. Disponível em < https://seer.ufrgs.br/EspacoAmerindio/issue/view/3633/showToc >, acesso em 17 abr. 2020.

BERBERT, Paula. 2017. "Para nós nunca acabou a ditadura": instantâneos etnográficos sobre a guerra do Estado brasileiro contra os Tikmüuñn_Maxakali. Dissertação de Mestrado em Antropologia. Belo Horizonte: Programa de Pós-Graduação em Antropologia, UFMG. Disponível em < https://www.academia.edu/38815644/_Para_n\%C3\%B3s_nunca_acabou_a_ditadura_ instant\%C3\%A2neos_etnogr\%C3\%A1ficos_sobre_a_guerra_do_Estado_brasileiro_contra_os_ Tikm\%C5\%A9_\%C5\%A9n_Maxakali>, acesso em 17 abr. 2020.

BORGONHA, Mirtes. 2006. História e etnografia Ofayé: estudo sobre um grupo indígena do centro-oeste brasileiro. Dissertação de Mestrado em Antropologia Social. Florianópolis: PPGAS/ UFSC. Disponível em <http://etnolinguistica.wdfiles.com/local--files/tese\%3Aborgonha-2006/ borgonha_2006.pdf>, acesso em 17 abr. 2020. 
CALHEIROS, Orlando. 2015. 'No tempo da guerra': algumas notas sobre as violações de direitos dos povos indígenas e os limites da justiça de transição no Brasil”, Verdade, Justiça, Memória RE-VISTA, Rio de Janeiro (RJ): ISER v. 10. Disponível em < https://www.academia. edu/17162202/_No_Tempo_da_Guerra_Algumas_notas_sobre_as_viola\%C3\%A7\%C3\%B5es_ dos_direitos_dos_povos_ind\%C3\%ADgenas_e_os_limites_da_justi\%C3\%A7a_de_ transi\%C3\%A7\%C3\%A3o_no_Brasil>, acesso em 17 abr. 2020.

CARNEIRO DA CUNHA, Manuela (Org.). 1992. História dos indios no Brasil. São Paulo (SP): Companhia das Letras.

CARNEIRO DA CUNHA, Manuela; BARBOSA, Samuel (orgs.). 2018. Direitos Indígenas em Disputa. São Paulo: Editora Unesp.

COLMAN, Rosa. 2017. "Ñemborambipa: deslocamentos forçados entre os Guarani em Mato Grosso do Sul”, Mediações 22(2): 51-71. Disponível em < https://www.nepo.unicamp.br/ publicacoes/anais/arquivos/21_RC.pdf>, acesso em 17 abr. 2020.

DAVIS, Shelton. 1978. Vitimas do milagre. O desenvolvimento e os indios do Brasil. Rio de Janeiro: Zahar Editores.

DANOWSKI, Deborah; VIVEIROS DE CASTRO, Eduardo. 2014. Há mundo por vir? Ensaios sobre os medos e os fins. Florianópolis, Desterro (SC): Cultura e Barbárie: Instituto Socioambiental.

DIAS FILHO, Antonio Jonas. 2015. Sobre os viventes do Rio Doce e da Fazenda Guarany: Dois presídios federais para indios durante a Ditadura Militar. Tese de Doutorado em Ciências Sociais, São Paulo. Programa de Estudos Pós-Graduados em Ciências Sociais, Pontifícia Universidade Católica de São Paulo. Disponível em < https://tede2.pucsp.br/handle/handle/3611>, acesso em 17 abr. 2020.

DUTRA, Carlos Alberto. 2004. O território ofaiépelos caminhos da história. Reencontro e trajetória de um povo. Dissertação de Mestrado em História. Dourados: Programa de Pós-Graduação em História, Universidade Federal de Mato Grosso do Sul. Disponível em <http://etnolinguistica.wdfiles.com/ local--files/tese\%3Adutra-2004/dutra_2004.pdf>, acesso em 17 abr. 2020.

FABIO, André Cabette. 2019. "O que há contra Bolsonaro no Tribunal Penal Internacional”, Nexo, Expresso, 29 nov. 2019. Disponível em <https://www.nexojornal.com.br/expresso/2019/11/29/Oque-h\%C3\%A1-contra-Bolsonaro-no-Tribunal-Penal-Internacional>, acesso em 17 abr. 2020.

FERNANDES, José L. 1958. Ofício n. 56/58 à Prof. Heloisa Alberto Torres, presidente do Conselho Nacional de Proteção aos Índios. Acervo do Círculo de Estudos Bandeirantes. Curitiba (PR).

FERNANDES, Pádua. 2013. “Segurança nacional e os povos indígenas, ontem e hoje: os documentos sigilosos da ditadura militar no Brasil e a jurisprudência atual do STF”. Comunicação apresentada no III Encontro Nacional de Antropologia do Direito (ENADIR), no GT 5/9 (Antropologia, direitos coletivos, sociais e culturais: questões indígenas, quilombolas e de comunidades tradicionais), Universidade de São Paulo, São Paulo (SP), 29 ago.

FIOROTT, Thiago H. 2017. A morte do Uatu: impactos do desastre da Samarco/Vale/BHP sobre a sustentabilidade do povo Krenak. Dissertação de Mestrado em Desenvolvimento Sustentável; Sustentabilidade junto a Povos e Terras Tradicionais. Brasília: Programa de Pós-graduação Profissional em Desenvolvimento Sustentável, UnB. Disponível em < https://repositorio.unb.br/ handle/10482/31199>, acesso em 17 abr. 2020. 
FARIAS, Elaise; KRENAK, Ailton. "Não é a primeira vez que profetizam nosso fim; enterramos todos os profetas" (Entrevista concedida à Elaise Farias). Amazônia Real. Disponível em <https:// amazoniareal.com.br/nao-e-a-primeira-vez-que-profetizam-nosso-fim-enterramos-todos-os-profetasdiz-ailton-krenak/>. Consulta em 18/02/2020.

GAGLIARDI, José Mauro. 1989. O indigena e a República. São Paulo (SP): Hucitec.

"GOVERNO brasileiro é denunciado na ONU por violações de direitos indígenas", Instituto Socioambiental, Povos Indigenas, 11 mar. 2014. Disponível em < https://www.socioambiental.org/ pt-br/noticias-socioambientais/governo-brasileiro-e-denunciado-na-onu-por-violacao-de-direitosindigenas >, acesso em 17 abr. 2020.

GUIMARÃES, Elena. 2015. Relatório Figueiredo: entre tempos, narrativas e memórias. Dissertação de Mestrado em Memória Social. Rio de Janeiro: Programa de Pós-Graduação em Memória Social/ Programa de Pós-Graduação em Memória Social, Universidade Federal do Estado do Rio de Janeiro. Disponível em < http://www.memoriasocial.pro.br/documentos/Disserta\%C3\%A7\%C3\%B5es/ Diss373.pdf >, acesso em 17 abr. 2020.

HECK, Egon. 1996. Os indios e a caserna: politicas indigenistas dos governos militares (1964-1985). Dissertação de Mestrado em Ciência Política. Campinas: Programa de Pós-Graduação em Ciência Política, Universidade Estadual de Campinas. Disponível em < http://repositorio.unicamp.br/ handle/REPOSIP/279393? mode=full $>$, acesso em 17 abr. 2020.

LEITE, Eudes Fernando; Oliveira, Jorge Eremites. 2012. “Faço parte da história desse jeito!': componentes da memória e da identidade de uma indígena guató”, Tellus 12(23):127146, jul./dez. Disponível em < file://C:/Users/Larissa/Downloads/261-Texto\%20do\%20 artigo-747-1-10-20141124.pdf>, acesso em 17 abr. 2020.

LIMA, Daniela B. 2012. 'Vamos amansar uns brancos para pegar as coisas'. Elementos da etnohistória Kajkhwakratxi-jê (Tapayuna). Dissertação de Mestrado em Antropologia Social. Brasília: Programa de Pós-Graduação em Antropologia Social. UnB. Disponível em < https://repositorio.unb.br/ handle/10482/22272>, acesso em 17 abr. 2020.

LIMA, Edilene C. 2017. "Exílios índios: sobre deslocamentos compulsórios no período militar (1964-1988)”, ACENO, Cuiabá (MT): PPGAS-UFMT, 3(6):18-35. Disponível em < http:// periodicoscientificos.ufmt.br/ojs/index.php/aceno/article/viewFile/4344/pdf>, acesso em $17 \mathrm{abr}$. 2020.

LIMA, Edilene C.; OLIVEIRA, Jorge Eremites (orgs.). 2017. Dossiê "Remoções forçadas de povos indígenas no Brasil Republicano", Mediações 22(2). Disponível em < http://www.uel.br/revistas/uel/ index.php/mediacoes/article/view/32254>, acesso em 17 abr.2020.

LIMA, Edilene C.; PACHECO, Rafael. 2017. "Povos Indígenas e Justiça de Transição: reflexões a partir do caso Xetá”, Aracê - Direitos Humanos em Revista, São Paulo (SP): Andhep, 4(5):219-241. Disponível em < https://arace.emnuvens.com.br/arace/article/view/143>, acesso em 17 abr. 2020.

MALABOU, Catherine. 2007. Les nouveaux blessés. Paris, Bayard.

MARINHO, Rafael Pacheco. 2018. Os Xetá e suas histórias: memória, estética, politica desde o exílio. Dissertação de Mestrado em Antropologia. Curitiba: Programa de Pós-graduação em Antropologia, UFPR. Disponível em <https://acervodigital.ufpr.br/handle/1884/62014>, acesso em 17 abr. 2020. 
MOREIRA NETO, Carlos Araújo. 1967. “Constante histórica do indigenato no Brasil”. Lent, Herman (ed.). Atas do Simpósio sôbre a Biota Amazônica Vol. II (Antropologia), p. 175-185, Rio de Janeiro (RJ), Conselho Nacional de Pesquisas. Disponível em < http://www.etnolinguistica.org/ biota:vol2p175-185>, acesso em 17 abr. 2020.

MOTA, Lúcio T. 1994. As guerras dos indios Kaingang: a história épica dos indios Kaingang no Paraná (1769-1924). Maringá: Eduem. Disponível em < https://www.academia.edu/25438069/ As_guerras_dos_\%C3\%ADndios_Kaingang>, acesso em 17 abr. 2020.

OLIVEIRA, Jorge Eremites de. 1995. Os argonautas Guató: aportes para o conhecimento dos assentamentos e da subsistência dos grupos que se estabeleceram nas áreas inundáveis do Pantanal Matogrossense. Dissertação de Mestrado em História, Concentração em Arqueologia. Porto Alegre: Programa de Pós-Graduação em História, Pontifícia Universidade Católica do Rio Grande do Sul. Disponível em <http://www.anchietano.unisinos.br/publicacoes/textos/oliveira1995/oliveira\%20 1995.pdf>, acesso em 17 abr. 2020.

OLIVEIRA, Jorge Eremites de. 1996. Guató: Argonautas do Pantanal. (Coleção Arqueologia, 2). Porto Alegre: EDIPUCRS. Disponível em <https://books.google.com.br/books?id=ht3s42hVwzE C\&pg=PA41\&lpg=PA41\&dq=guat $\% \mathrm{C} 3 \% \mathrm{~B} 3+$ etnologia\&source $=$ bl\&ots $=$ mf13F7bDHD\&sig $=$ ACfU3U1vxqnhy4NrP-LBYlUK1V4JTAW9IQ\&hl=pt-BR\&sa=X\&ved=2ahUKEwjF35a3wu oAhWZF7kGHXwlDokQ6AEwCXoECAwQKw\#v=onepage\&q=guat\%C3\%B3\%20 etnologia\&f=false>, acesso em 17 abr. 2020.

OSOWSKY, Raquel. 2017. "O marco temporal para demarcação de terras indígenas, memória e esquecimento", Mediações 22(2): 320-346. Disponível em <http://www.uel.br/revistas/uel/index. $\mathrm{php} /$ mediacoes/article/viewFile/32261/pdf>, acesso em 17 abr. 2020.

PACHECO, Rosely A. S. "A violência contra os povos indígenas: uma estrutura invisível que impõe a fronteira entre a vida e a morte", PROEX/UFMG. Disponível em <https://www2.ufmg.br/proex/ Noticias/Noticias/um-seculo-de-luta-Krenak>.

PRADO, Felipe S. 2018. O processo de militarização das políticas indigenistas na ditadura civilmilitar brasileira. Dissertação de Mestrado em Estudos Latino-Americanos. Foz de Iguaçu: Programa de Pós-Graduação Interdisciplinar em Estudos Latino-Americanos, Universidade Federal da Integração Latino-Americana. Disponível em < https://dspace.unila.edu.br/bitstream/ handle/123456789/4980/O\%20PROCESSO\%20DE\%20MILITARIZA\%C3\%87\%C3\%83O\%20 DAS\%20POL\%C3\%8DTICAS\%20INDIGENISTAS\%20NA\%20DITADURA\%20CIVILMILITAR\%20BRASILEIRA.pdf ?sequence=1 \&isAllowed=y>, acesso em 17 abr. 2020.

PIERRI, Daniel. 2014. "A reparação e o desagravo que falta aos povos indígenas", Folha de S. Paulo, Opinião, 23 set. 2014. Disponível em https://www1.folha.uol.com.br/opiniao/2014/09/1520391daniel-pierri-a-reparacao-e-o-desagravo-que-falta-aos-povos-indigenas.shtml, acesso em 17 abr. 2020.

PIERRI, Daniel; ZELIC, Marcelo. 2014. "Povos indígenas na mira da ditadura e do Congresso", Folha de S. Paulo, Tendências e Debates, 17. dez. 2014. Disponível em < https://www 1.folha.uol. com.br/opiniao/2014/12/1563338-daniel-calazans-pierri-e-marcelo-zelic-povos-indigenas-na-mirado-congresso.shtml?cmpid=menutopo $>$, acesso em 17 abr. 2020.

RAMOS, Alcida R. 1993. "O papel político das epidemias: o caso yanomami”, Série Antropologia 153, Brasília (DF): Departamento de Antropologia, UnB. Disponível em < http://sis.funasa.gov.br/ portal/publicacoes/pub365.pdf>, acesso em 17 abr. 2020. 
RESENDE, Sarah Mota. 2018. “No que depender de mim, não tem mais demarcação de terra indígena,' diz Bolsonaro na TV”, Folha de S. Paulo, Poder, 05 nov. 2018. Disponível em < https:// www1.folha.uol.com.br/poder/2018/11/no-que-depender-de-mim-nao-tem-mais-demarcacao-deterra-indigena-diz-bolsonaro-a-tv.shtml>, acesso em 17 abr. 2020.

SILVA, Carmen L. 1998. Sobreviventes do exterminio - uma etnografia das narrativas e lembranças da sociedade Xetá. Dissertação de Mestrado em Antropologia Social. Florianópolis: Programa de Pós-Graduação em Antropologia Social, Universidade Federal de Santa Catarina. Disponível em < https://repositorio.ufsc.br/handle/123456789/77661>, acesso em 17 abr. 2020.

STENGERS, Isabelle. 2015. No Tempo das Catástrofes. São Paulo: Cosac Naify. (Coleção EXIT).

TOMAZI, Nelson D. 1997. "Norte do Paraná": História e Fantasmagorias. Tese de Doutorado em História. Curitiba: Universidade Federal do Paraná. Curitiba (PR). Disponível em < https:// acervodigital.ufpr.br/bitstream/handle/1884/31883/T\%20-\%20NELSON\%20DACIO\%20 TOMAZI.pdf ?sequence=1>, acesso em 17 abr. 2020.

VALENTE, Rubens. 2017. Os fuzis e as flechas - histórias de sangue e resistência indígena na ditadura. São Paulo (SP): Companhia das Letras.

VIVEIROS DE CASTRO, Eduardo B. 2016. "Sobre a noção de etnocídio, com especial atenção ao caso brasileiro”. Disponível em < https://www.academia.edu/25782893/Sobre_a_ no\%C3\%A7\%C3\%A3o_de_etnoc\%C3\%ADdio_com_especial_aten\%C3\%A7\%C3\%A3o_ao_ caso_brasileiro>, acesso em 17 abr. 2020.

ŽIŽEK, Slavoj. 2012. Vivendo no Fim dos Tempos. São Paulo (SP): Boitempo Editorial.

RECEBIDO: $16 / 02 / 2020$

APROVADO: $19 / 02 / 2020$ 